\title{
Basic Research Tools for Earthworm Ecology
}

\author{
Kevin R. Butt and Niki Grigoropoulou \\ School of Built and Natural Environment, University of Central Lancashire, Preston PR1 2HE, UK \\ Correspondence should be addressed to Kevin R. Butt, krbutt@uclan.ac.uk
}

Received 24 June 2009; Accepted 9 September 2009

Academic Editor: Natchimuthu Karmegam

Copyright ( 2010 K. R. Butt and N. Grigoropoulou. This is an open access article distributed under the Creative Commons Attribution License, which permits unrestricted use, distribution, and reproduction in any medium, provided the original work is properly cited.

\begin{abstract}
Earthworms are responsible for soil development, recycling organic matter and form a vital component within many food webs. For these and other reasons earthworms are worthy of investigation. Many technologically-enhanced approaches have been used within earthworm-focused research. These have their place, may be a development of existing practices or bring techniques from other fields. Nevertheless, let us not overlook the fact that much can still be learned through utilisation of more basic approaches which have been used for some time. New does not always equate to better. Information on community composition within an area and specific population densities can be learned using simple collection techniques, and burrowing behaviour can be determined from pits, resin-insertion or simple mesocosms. Life history studies can be achieved through maintenance of relatively simple cultures. Behavioural observations can be undertaken by direct observation or with low cost webcam usage. Applied aspects of earthworm research can also be achieved through use of simple techniques to enhance population development and even population dynamics can be directly addressed with use of relatively inexpensive, effective marking techniques. This paper seeks to demonstrate that good quality research in this sphere can result from appropriate application of relatively simple research tools.
\end{abstract}

\section{Introduction}

There is no need to make a case for studying earthworms, as their role within the soil has been recognized for more than a century [1]. Collectively, these organisms are able to pass vast quantities of soil through their guts and by doing so bring about the creation of an improved crumb structure which incorporates mineral and organic elements and can become a seedbed for plant growth [2]. In addition, earthworms may aerate soils and increase water infiltration, hence reducing soil erosion, by burrow creation [3]. On top of all this some species are more highly regarded as they are attributed with ecosystem engineering capabilities; that is, they are able to directly influence the environment around themselves and the availability of resources to other organisms [4].

Many avenues of research are available and this article could very easily seek to review and critique some of the more advanced techniques currently in use within the sphere of earthworm ecology. These might include DNA-related work examining the genome of selected species [12]; ecotoxicology, following the accumulation of, for example, heavy metals in the tissues of earthworms on contaminated land
[13]; or, for example, isotopic work, looking at the transfer of radio-labelled elements through earthworm-linked food chains [14]. However, such relatively high-tech methods will not be the focus of this work, which seeks to generally avoid reliance upon potentially costly and high-maintenance equipment. This article actually aims at doing one thing; it seeks to show that the use of low-technology methods is still able to gain insights into fundamental questions relating to earthworms. Much is still to be fully understood about this group, and although many advances have recently been made using sophisticated, expensive equipment/techniques, there is still room for the under-resourced professional or educated amateur to make a serious contribution. To demonstrate this, the article focuses on the following: a description of simple collection techniques, which can assist in revealing a great deal of earthworm community structure, followed by investigation of a major earthworm activity_-burrowing and then a close inspection of earthworm life history and behaviours. Each aspect will hopefully show that basic techniques exist within earthworm ecology that can reveal previously unknown information and assist in building a more comprehensive picture of this important animal group. 
TABLE 1: Recent British examples of earthworm density/biomass/community structure from sampling with the same techniques (digging and application of a mustard vermifuge).

\begin{tabular}{|c|c|c|c|c|c|c|c|}
\hline Location & Habitat & $\begin{array}{l}\text { Sampling } \\
\text { date }\end{array}$ & $\begin{array}{l}\text { Earthworm } \\
\text { density (No } \\
\mathrm{m}^{-2} \text { ) }\end{array}$ & $\begin{array}{l}\text { Earthworm } \\
\text { biomass } \\
\left(\mathrm{gm}^{-2}\right)\end{array}$ & Earthworm species & $\begin{array}{l}\text { Dominant } \\
\text { species }\end{array}$ & Reference \\
\hline $\begin{array}{l}\text { Aughton Woods, } \\
\text { Lancs }\end{array}$ & $\begin{array}{l}\text { Deciduous } \\
\text { woodland }\end{array}$ & Oct 2006 & 37 & 29.8 & Ach; Dr; Lt; Oc & Oc & {$[5]$} \\
\hline $\begin{array}{l}\text { Aughton Woods, } \\
\text { Lancs }\end{array}$ & Pasture & Oct 2006 & 183 & 110.9 & Ach; Ac; Al; Ar; Lr; Lt; Oc & Ac & {$[5]$} \\
\hline $\begin{array}{l}\text { Meresands Wood, } \\
\text { Lancs }\end{array}$ & Dry Heathland & Oct 2001 & 167 & 75.0 & Ach; Ac; Al; Ar; Et; Lc; Lr; Lt; Oc & Ac & {$[6]$} \\
\hline $\begin{array}{l}\text { Wistman's Wood, } \\
\text { Devon }\end{array}$ & $\begin{array}{l}\text { Upland oak } \\
\text { woodland }\end{array}$ & May 1999 & 13 & 9.3 & Le; Lr; Dr & Dr & {$[7]$} \\
\hline Down House, Kent & Pasture & March 2004 & 310 & 149.6 & Ach; Al; Ar; Lr; Ot; Sm & $\mathrm{Ot}$ & {$[8]$} \\
\hline Down House, Kent & Kitchen Garden & March 2004 & 715 & 261.0 & Ach; Ac; Al; Ar & Ach & {$[8]$} \\
\hline $\begin{array}{l}\text { Isle of Rum, } \\
\text { Scotland }\end{array}$ & $\begin{array}{l}\text { Upland } \\
\text { moorland }\end{array}$ & May 2000 & 9 & 3.0 & Do; Dr; Lr & Dr & {$[9]$} \\
\hline $\begin{array}{l}\text { Malham Tarn, } \\
\text { Yorkshire }\end{array}$ & Pasture & May 1998 & 291 & 86.1 & Ach; Ac; Al; Ar; Do; Lc; Lt; Oc & Ach & {$[10]$} \\
\hline Newton Rigg Farm & Winter Barley & April 2006 & 18 & 6.0 & Ach; Al & $\mathrm{Al}$ & {$[11]$} \\
\hline Newton Rigg Farm & $\begin{array}{l}\text { Conservation } \\
\text { Headland }\end{array}$ & April 2006 & 118 & 76.2 & Ach; Ac; Al; Ar; Do; Lr; Oc: Sm & $\mathrm{Al}$ & {$[11]$} \\
\hline
\end{tabular}

Key: Ach: Allolobophora clorotica; Ac: Aporrectodea caliginosa; Al: Aporrectodea longa; Ar: Aporrectodea rosea; Do: Dendrobaena octaedra; Dr: Dendrodrilus rubidus; Et: Eiseniella tetraedra; Lc: Lumbricus castaneus; Le: Lumbricus eiseni; Lr: Lumbricus rubellus; Lt: Lumbricus terrestris; Oc: Octolasion cyaneum; Ot: Octolasion tyrtaeum; Sm: Satchellius mammalis.

\section{Collection Techniques (First Catch Your Earthworm)}

It is often desirable to quantify earthworm number or biomass in a given habitat and/or seek to collect them. A few species show their presence by surface casting (e.g., Aporrectodea longa) or creation of middens (e.g., Lumbricus terrestris) but most require some form of intervention to locate them, due to their totally subterranean existence. To this end, various techniques have been developed to enable earthworm collection. Digging is the simplest, as it requires only a spade and perhaps a quadrat for density calculations but may detect only near surface (epigeic) earthworms and horizontal burrowing (endogeic) species. Adults of deeper burrowing (anecic) species may be missed unless the researcher is prepared to dig a hole to a depth of several metres!

An alternative to digging is the application of a vermifuge (expellent), which when poured on to the soil drives earthworms to the surface as it acts as a skin irritant when contacted in their burrows (direct application, e.g., via a syringe to $L$. terrestris burrows may be very effective). Various chemicals have been used, with a dilute solution of formaldehyde (formalin) currently recognized as a standard [15], but as this has been reported as carcinogenic, further options have been sought. It is also suggested [16] that there are severe negative effects to other soil fauna, soil respiration, and vegetation cover if formaldehyde is applied. A suspension of table mustard in water has been used [17], but tests [10] have shown that a suspension of mustard powder (e.g., $50 \mathrm{~g}$ in 10 litres water) is both cheaper and more effective. More recently use of "hot" mustard has been used to give a more consistent index of earthworm abundance across a range of soil types [18]. As the type of mustard may also affect results, an extract derived from mustard seed Allyl isothiocyanate (AITC) has been used for earthworm collection [19]. AITC has recently been shown as a reliable and promising chemical expellant whether or not used in combination with handsorting [20]. Many researchers now advocate that the most effective collection technique is indeed a combination of digging and hand-sorting of soil (deposited e.g., on a plastic sheet in the field) followed by application of a vermifuge to the hole created $[10,20]$. Different techniques have in the past given rise to differential collection of species and provided results which are not directly comparable. By contrast, Table 1 provides recent examples of data relating to earthworm density, biomass, and community structure from a variety of British habitats using the same combination of digging and mustard application for collection.

Another collection method is application of an electrical current to the soil. This method is attractive as little or no damage is done to the area sampled and only fallen leaves and overgrown vegetation need be removed prior to sampling to assist earthworm detection. To date only limited work has been undertaken with this method, specifically in agricultural soils [21] possibly because equipment is expensive as an extraction unit to sample $0.2 \mathrm{~m}^{2}$ at a time will cost (at 2009 prices) in excess of $\$ 3000$. 


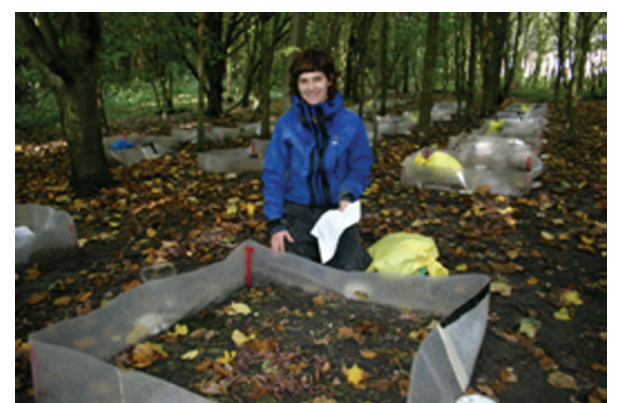

Figure 1: Earthworm enclosures $\left(1 \mathrm{~m}^{2}\right)$ used for manipulating density of Lumbricus terrestris in managed woodland (earthworms added to enclosure in foreground).

Having determined which earthworms are present in a given habitat, if desired, it is then possible to experimentally manipulate the earthworms themselves or resources, such as food, in the habitat. Several studies have used field enclosures to investigate the effects of earthworms on soil properties and plants $[22,23]$. Such enclosures can be formed with PVC walls, buried in slit trenches to a depth of up to $45 \mathrm{~cm}$ and a height of $15 \mathrm{~cm}$ above the soil surface. These have been shown to act as effective barriers to lateral earthworm movements. Results have suggested that both earthworm removal and addition of field-collected earthworms within enclosures can be an effective and useful approach for assessing the influence of earthworms on ecosystem processes (see Figure 1).

Associated with earthworm enclosures is a novel method ("tunnel" trapping) that can be used to observe and record emigration of earthworms. Trap units can be combined with earthworm fencing in the field [24], or with mesocosms in laboratory experiments allowing examination of emigration rates, while manipulating biotic and abiotic factors (e.g., population density, community structure, predation, resources availability, temperature, precipitation).

Tunnel traps can be prepared using 1 litre plastic pots with mounted needle-perforated lids. Holes $(r=6 \mathrm{~mm})$ drilled in these smaller "capture pots" just below the lid allow insertion of PVC tubing ( $10 \mathrm{~mm}$ ID, $5 \mathrm{~cm}$ long) to connect to either earthworm fencing in field enclosures or larger soil-filled mesocosms. Surface migrating species can move from enclosures/mesocosms into traps via the tubing that is aligned at the soil surface (Figure 2). Movement of captured individuals back into containers is prevented by filling capture pots with soil or other suitable medium to half of their total volume. Providing acceptable conditions (e.g., soil and food) in capture pots can allow earthworms to survive for long periods therefore permitting relatively infrequent examination. Tunnel traps have been successfully used in both field and laboratory experiments which aimed to examine dispersal of the anecic $L$. terrestris as affected by population density and resources availability [24].

The types of simple investigation associated with earthworm sampling should allow some of the following questions to be answered.

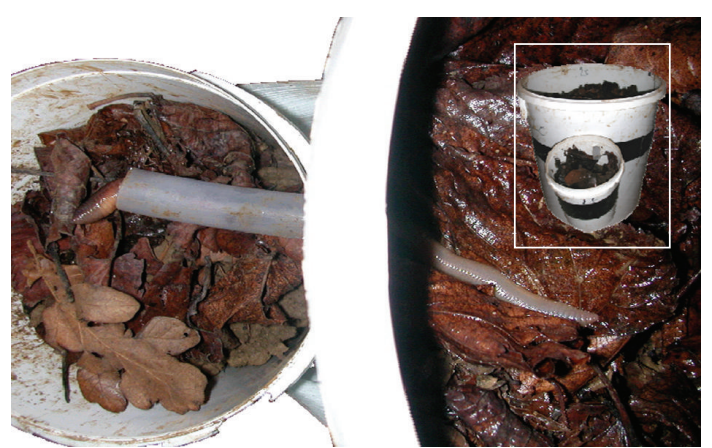

FIgURE 2: Plan view of a tunnel trap showing a mature $L$. terrestris exiting a 20-litre mesocosm into the attached 1-litre capture pot (lids removed). Insert shows a lateral view of the whole setup.

(i) Which species of earthworms are present within the community in the given habitat?

(ii) At what densities (number $\mathrm{m}^{-2}$ ) and biomasses $\left(\mathrm{gm}^{-2}\right)$ are these animals present?

(iii) What proves to be the most efficient method for collection of given earthworm species?

(iv) Can populations be experimentally manipulated to test density-related hypotheses (using addition/removal, fencing, and trapping)?

\section{Burrowing and Burrow Morphology}

As with unearthing which species are present, as previously described, working out which species are active and at what depths is not so simple. Again, it usually requires some form of intervention as many earthworms are relatively small and generally live below the surface of the soil. However, some species do proclaim their presence by depositing their casts (faeces) on the soil surface. This is particularly true of larger species which may be digging burrows and have relatively large amounts of earth to dispose of and others which are almost constantly "head down" and "bottom up" producing surface casts. In temperate soils a good example of this is Aporrectodea longa (the black-headed or long worm). When present at high densities, this species is capable of almost totally covering the grass surface of a pasture with casts. It has been suggested that the amount of casting could even be used as a proxy for the density of (known casting) species present in an area [25]. Where the spread of $A$. longa was being followed, after introduction to an unpopulated site, casting activity was used to follow dispersal of this species through the soil over many years $[26,27]$. Another deep burrowing earthworm which provides signs of its presence on the soil surface is $L$. terrestris. This species constructs "middens" and these structures are normally engineered above the opening of the near vertical burrow used by this animal. Scientists have been aware of such structures since Darwin's day, but the precise function is still uncertain. Middens consist of organic (e.g., leaf) and inorganic (e.g., pebble) materials gathered together by the 
resident earthworm and often cemented together with casts. Regulation of burrow temperature and moisture content may be an obvious function, but protection from predators and provision of a food store (a minicompost heap) may be others [28]. Whichever way, the midden and associated burrow forms an integral part of the life of this relatively sedentary earthworm. Recent work [29] has also revealed that many other earthworm species are associated with L. terrestris middens compared with adjacent nonmidden soil; so middens may play a major part in determining distribution of other earthworms at a microscale.

Nevertheless, most earthworms are mainly active below the soil surface; so most investigations need to proceed within the soil. Using burrows that open at the surface, such as those of $L$. terrestris, is one way. Observations have shown that large burrows (often referred to as macropores; diameter $8-10 \mathrm{~mm}$ ) may have the capacity to accept relatively large volumes of rainwater and assist with prevention of surface soil erosion. Testing of this type of water entry into the soil is easily undertaken. The simplest method is to create a water-tight, isolated area at the soil surface (an infiltration "ring") covering a known surface area and then add a known volume of water to that area and record the time taken for all water to enter the soil. Comparing different areas within a given habitat/field can be very revealing, particularly when coupled with earthworm collection from the same areas. A slight elaboration on this technique is to use a vertical column of water (Marriot device) which can be fed directly into a single burrow. Such work investigated the burrow systems of $L$. terrestris in agricultural systems [30]. Infiltration of water into burrows was examined with the resident earthworm present or after its removal (with a vermifuge) - the earthworm itself forming something of a plug. To further quantify and equate water ingress with burrow morphology, efforts were made to assess the volume of individual burrows. This was finally achieved by the use of a polyurethane resin, poured down the burrow and allowed to set hard [30]. Subsequently the solid representation of the burrow void was dug out by excavation of a pit alongside. Use of coloured pigment within the resin makes visual inspection in situ and after extraction much easier [31] (see Figure 3). A simpler technique than use of resin is use of coloured dyes. Dyes such as methylene blue in water can be poured into burrows or cracks in the soil [3] and then the area around excavated to see the extent of burrow systems present.

If access to a large digging machine is possible, then excavation of a pit in any soil can be very revealing. As mentioned "resin-cast" burrows can be revealed, but unadulterated burrows, if large enough, may also be seen. For example, during an investigation undertaken during a period of frost depth to $0.5 \mathrm{~m}$, [32] it was possible to follow burrows down to a depth of $1 \mathrm{~m}$ by "picking away" at the exposed soil profile with knives. This investigation, more interestingly, revealed much on the behaviour of $L$. terrestris and the (usually) shallow working Aporrectodea caliginosa during relatively cold periods. However, should it prove impossible to create a large soil pit, then it is possible to consider the activities of earthworms under more controlled conditions in a nonfield setting.

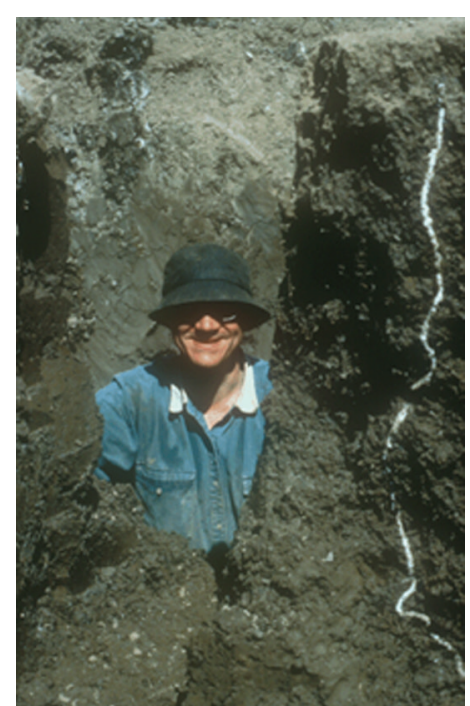

FIgURE 3: A burrow of Lumbricus terrestris filled with whitecoloured resin and exposed in the soil profile to its terminal depth at $1 \mathrm{~m}$.

A soil pit exposes a cut surface through the soil profile, which is in essence a 2-dimensional view. This can be recreated by production of what might be viewed as a "wormery" - a structure comprising 2 sheets of glass separated by a very small distance, for example, 5-8 $\mathrm{mm}$. Such structures not only have in the past been sold for domestic use (by children) to observe earthworms but also have a more research-focussed application. Early work [33] allowed use of such structures to observe the burrow formation of earthworms, and more recently these "Evans' boxes" - also referred to as 2D mesocosms - have been used [34] for similar aims but more specific objectives (see Figure 4). These workers examined the burrowing of $L$. terrestris but were specifically interested in the interactions between the various life stages of this species and found, until then, previously unrecorded aspects of cocoon deposition in side chambers and encasement of these cocoons with castings (see Figure 5). Such findings clearly demonstrate that observations of this type can reveal burrow-related behaviours which may have some significance in the life of these animals and not have been recognised before, even though this is a very well-studied species [28]. Table 2 shows some of the experimental data also gathered from this investigation.

Other ways of tracking earthworm burrows and assessing burrowing behaviours under controlled conditions are available and might be thought more appropriate as they do not occur in two dimensions. Soil cores can be extracted from the field (within suitable housing such as plastic cylinders), for example, by driving these into the soil from above and then maintaining them for the desired purpose. This may be to examine earthworm communities within and how they may assist other ecosystem process, for example, by comparing intact cores with those frozen to remove earthworms. Relatively recently, use of X-ray tomography 
TABLE 2: Details of cocoons and hatchlings of Lumbricus terrestris (mean \pm SD) produced under a number of adult manipulations in Evans' boxes, kept at $17^{\circ} \mathrm{C}$ in darkness (CTRL: no manipulation; CLtRm: earthworm removed and reintroduced; LtRp: earthworm removed and replaced by another; LtRm: earthworm removed—adapted from [34]).

\begin{tabular}{lcccc}
\hline Treatment & CTRL & CLtRm & LtRp & LtRm \\
\hline Total cocoons & $27.8 \pm 2.2$ & $24.8 \pm 9.0$ & $26.2 \pm 7.3$ & $12.6 \pm 2.7$ \\
No spent cocoons & $2.0 \pm 2.2$ & $3.3 \pm 2.6$ & $5.4 \pm 3.0$ & $1.8 \pm 2.5$ \\
Hatchlings & $1.8 \pm 2.9$ & $2.5 \pm 3.1$ & $2.2 \pm 1.6$ & $1.6 \pm 1.8$ \\
Hatchling survival (\%) & $67 \pm 29$ & $71 \pm 34$ & $47 \pm 33$ & $67 \pm 24$ \\
Hatchling mass (g) & $0.19 \pm 0.22$ & $0.09 \pm 0.06$ & $0.10 \pm 0.04$ & $0.40 \pm 0.38$ \\
\hline
\end{tabular}

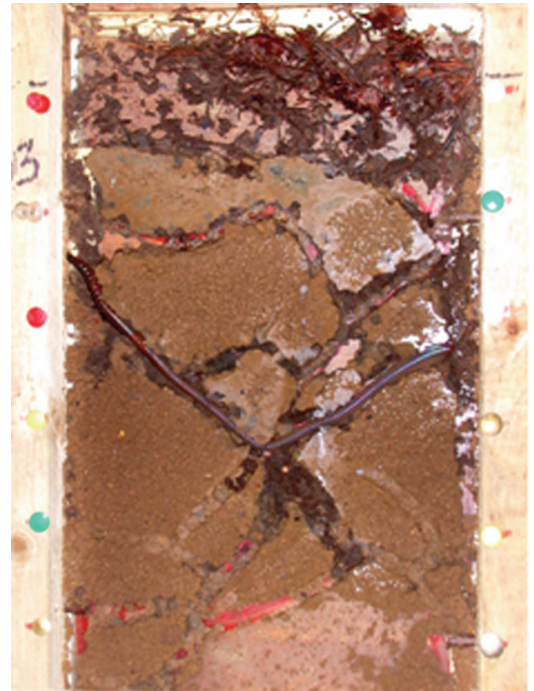

FIGURE 4: Upper $30 \mathrm{~cm}$ showing view through the glass side of an $80 \mathrm{~cm}$ deep Evans' box used to examine burrowing behaviour of a single mature L. terrestris (the adult can be seen across the centre).

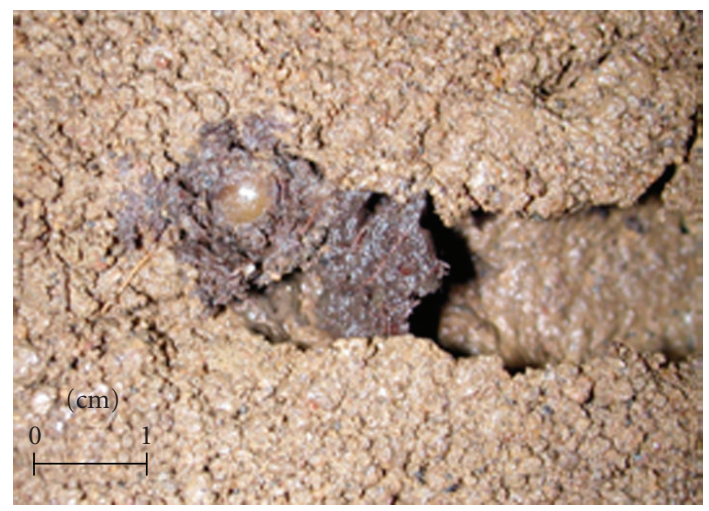

FIgURE 5: Detail of a side burrow with $L$. terrestris cocoon encased in parental casting seen in an Evans' box with one glass side removed (to permit better photography).

[35] has been used to determine burrow configurations in such cores. Whilst this may be a useful tool; it is one which required access to hospital-grade equipment so it cannot be considered basic. However soil cores can be utilised to study relatively simple "ecosystems" with earthworms as a component. These may allow examination of different animal species present and also plants growing at the soil surface, if kept in glasshouses. Inputs and out flows could also then be measured in simple terms. Taken to extreme lengths, researchers have developed systems such as the "Ecotron" [36] which has incorporated earthworms into its experimental systems but this facility was produced at a cost of $\$ 1.5$ million. Despite this cost and sophisticated equipment for measuring in and out flows of gases and liquids, the choice of earthworm species, as a part of a biodiversity and ecosystem behaviour experiment [37], may not have been appropriate to the given mesocosms. Once again, a situation, where most expensive and modern, does not necessarily mean most appropriate and insightful. Much more simple investigations in sealed mesocosms (pots) may not give rise to the bigger ecosystem "picture" but may provide good data on earthworm life histories (see below).

Surface-related and burrow-associated investigations might enable some of the following questions to be addressed.

(i) Which species are present at which horizons/depth in the soil profile?

(ii) What can be learned from earthworm activities at the soil surface?

(iii) Do burrows assist water infiltration?

(iv) How can earthworm burrow extent and volume be measured?

(v) Can the field (cores) be brought into and utilised in a controlled setting?

(vi) Can mesocosms be used to observe earthworms burrowing behaviour more closely?

\section{Life History Studies}

Many species have been well documented and much is known of their life history, but for example, ask any researcher to tell you what age an earthworm can live to, or which life stage is responsible for dispersal and you may find that no simple answer is forthcoming (even for L. terrestris). Great scope exists for gathering fundamental information on aspects of the life histories of most earthworm species. In Britain, where earthworms are reasonably well documented and a synopsis of species has been available in a number 
of revised forms for over 60 years [38, 39], information is still lacking in a number of quarters. For example, Dendrobaena attemsi is described from a single British record from Cumbria; yet we have collected this species easily from wooded areas on the Isle of Rum in Scotland. Equally for the same species, and more importantly with respect to life history, entries such as "presumably biparental" and "capsules unrecorded" [39] show that much is still to be learned-and perhaps this can be achieved relatively simply.

Wherever a researcher is based, there will be opportunities to collect local species of earthworm, as previously described. Providing that identification is not a problem, there are then chances to answer basic questions on the life history of the species. Using the soil from where the animals were collected, it should be possible to maintain them in containers of a chosen size, appropriate for the given species and its ecological group. The situation is to then ask relevant questions and seek to answer these through segregation of life stages and sampling at given time intervals. An initial question might relate to the mode of reproduction shown by the given species; is it amphimictic (requiring sexual reproduction) or parthenogenetic? To solve this, in the least amount of time, immature individuals need to be isolated and kept thus until they mature. This will naturally require consideration of their requirements in terms of, for example, soil, food, moisture, temperature, and space [40]. Inspection at appropriate time periods, monthly, weekly, or more frequently for rapidly maturing animals will determine when maturity (possession of a swollen clitellum) is reached. At this point the animals might usefully be subdivided into two groups $1: 2$. The smaller third should be left in isolation and the larger two-thirds put into groups of two to give an equal number of singletons and pairs. These labelled containers can then be monitored for cocoon production over the following weeks.

Sampling for cocoons can be straightforward and require a water supply and a mesh of appropriate size-depending on cocoon size-which is a function of clitellum diameter. Contents of containers in which adults have been kept can be sieved to obtain cocoons. These can then be incubated in Petri dishes, or equivalent, on moistened filter paper or similar at an appropriate temperature for the given species [40] (Figure 6). If animals have been kept, for example, in soil columns, then the depth at which cocoons are deposited might be considered by sieving away different levels from the column (more easily achieved if the cylinder in which they are housed is presplit (and taped together) along its length [41]). Incubation of cocoons can then occur and time to develop and hatch can be monitored. To obtain cocoons more rapidly for any species, mature animals which are fieldcollected can be employed directly in cocoon production studies and number produced per individual per time can be recorded from the given conditions under which they are maintained. Cocoons may be kept in groups or individually (depending on space available). The advantage of individual incubation is that the number of hatchlings can more easily be assessed, as many epigeic species produce more than one hatchling per cocoon. To complete life cycle records, growth of hatchlings to maturity can be assessed. This requires the

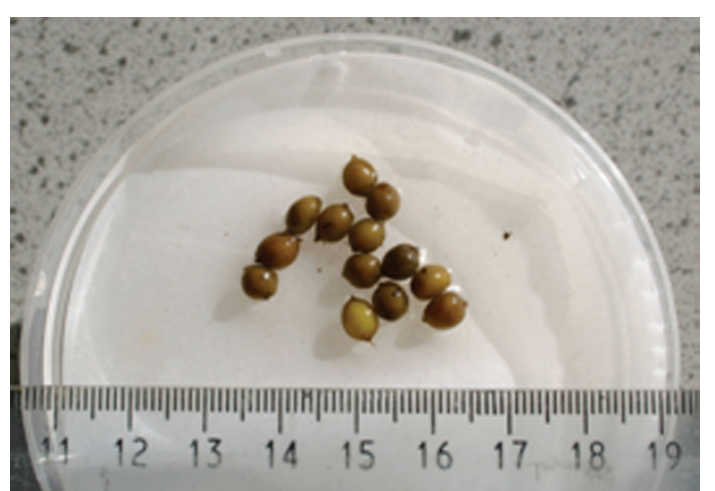

Figure 6: Freshly produced cocoons of $L$. terrestris housed on a moistened filter paper in a Petri dish. These were produced by 1 earthworm over 1 month.

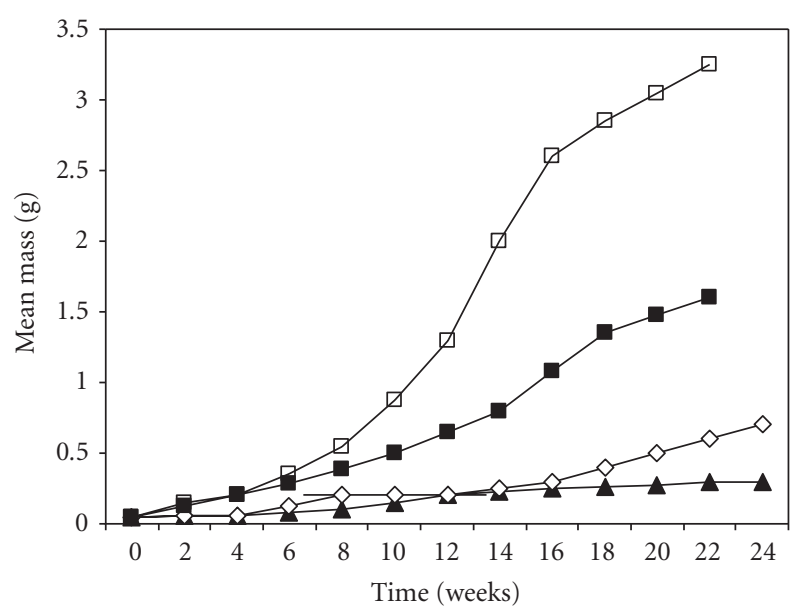

FIGURE 7: Typical earthworm growth curves obtained from periodic measurement of masses. Here Lumbricus terrestris was examined under constant temperature conditions $(\square-20$; $\square-15$; $\diamond-10$; $\Delta-5^{\circ} \mathrm{C}$; adapted from [44]).

type of conditions previously described but with periodic monitoring (and mass determination) until maturity is reached (see Figure 7 for typical results). Manipulation of biotic and abiotic factors influencing the growth and reproduction of the earthworms, such as population density [42], food quality [40], interspecific interactions [43], temperature [44], and a host of others and combinations thereof, can be considered. Finally to ascertain the age to which earthworms can live, animals might need to be kept for some time.

One relatively simple technique that might assist life history/population studies is the ability to permanently mark (tag) individual earthworms. Recent work [45] has shown that it is possible, through injection of Visual Implant Elastomer (VIE), available from Northwest Marine Technology [46] to visually colour tag earthworms. In addition these tags have been shown to be retained in a number of earthworm species for more than 2 years and have no detrimental effects on growth to maturity, mating, and cocoon production in one closely studied species, L. terrestris [47]. This technique 
may well prove to be valuable in earthworm age determination but may also reveal much from studies of population dynamics, in terms of capture, mark recapture exercises. Tagging captured animals and then recapture data could assist in learning much more of these organisms particularly in a variety of habitats. Cohorts of the same species could be tagged with different colours in different years to permit a better understanding, for example, of survival. Used in combination with density manipulation experiments, this type of exercise has already revealed aspects of $L$. terrestris dispersal and settlement under field conditions in managed woodland plots [24]. It should be noted that at current (2009) prices, this material is relatively inexpensive, with a trial pack of VIE costing \$42. Such an amount will permit tagging of hundreds of earthworms (see Figures 8(a) and $8(\mathrm{~b})$ ).

By collecting earthworms and maintaining them under controlled environmental conditions, it ought to be possible to answer most of the following questions on life histories.

(i) What mode of reproduction is exhibited by a given species?

(ii) Where in the soil are cocoons produced?

(iii) How long does cocoon incubation take before hatching occurs?

(iv) How many hatchlings are produced per cocoon?

(v) How long does it take for growth to maturity and at what mass is this reached?

(vi) Which factors (biotic or abiotic) may have a major influence on the above?

(vii) To what age does this species live?

\section{Behavioural Studies}

Many activities of earthworms, known for decades, still present uncertainties in terms of interpretation. Equally, where glimpses of the subterranean world are provided, much can be learned. Some behaviours relating to burrowing and casting have already been discussed; so this section will concentrate on just a small number of behaviours, such as mating and dispersal and focus on techniques which may be of use to further investigate them. Many authors have reported mass emergence and dispersal of earthworms [2]. The timing of this may be seasonal or associated with particular weather conditions. The species concerned may vary but perhaps this behaviour has a common underlying cause? Often occurring at night, in urban settings it might normally go unnoticed, but for the fact that "stranded" earthworms may be found the following morning on surfaces such as concrete or tarmac, into which they are unable to burrow.

En masse emergence of earthworms may often follow periods of rain. Opinions vary, but some suggest that this is a function of earthworms exiting their burrows as a response to inundation which might lead to potential death. We dispute this idea, as earthworms are able to survive

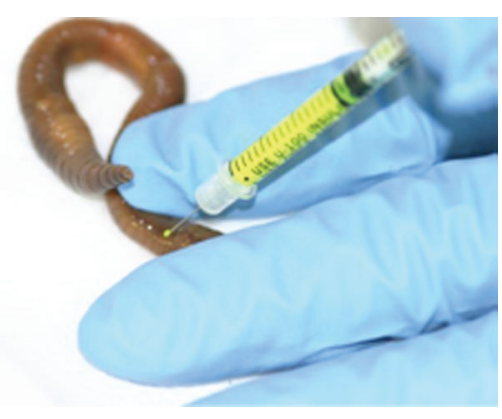

(a)

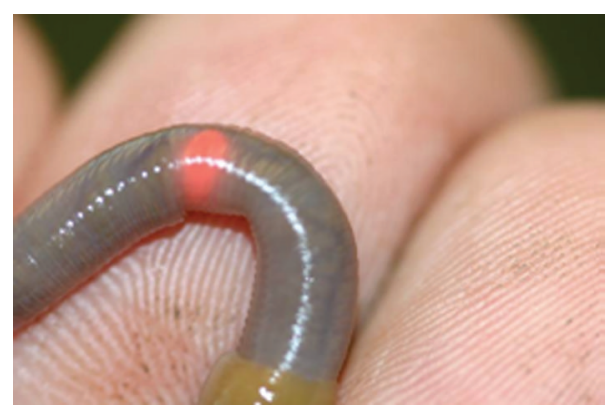

(b)

Figure 8: (a) Injection of yellow Visual Implant Elastomer (VIE) into Lumbricus terrestris; (b) Octolasion cyaneum with a red VIE tag inserted.

lengthy periods of submergence in water, and support the hypothesis [28] that it is more closely related to dispersal. A question posed earlier related to the life stage at which earthworms disperse. Perhaps other related questions that need addressing are why would earthworms seek to disperse and what factors might encourage this? The "why" part may relate directly to evolutionary biology. Even though they are hermaphrodite, many earthworm species show sexual reproduction. Therefore mating may normally occur with near neighbours. To bring about greater possible exchange of genetic material and avoid inbreeding, movement away from place of birth (dispersal) is required at some point in the life cycle. This then moves on to the "how" part. Movement through the soil is slow and may only average a few metres per year [26,48], but over surface movement by earthworms may be much more rapid [49]. To this end, some earthworm species may utilise periods following rain to disperse as the wet conditions prevailing will enhance movement across the soil surface and decrease the chances of desiccation and death from exposure. It could be argued that such behaviour would not therefore be found in parthenogenetic species if this were the only reason for emergence, and this is not the case as Octolasion cyaneum is such a species regularly located on the surface after some rains. Nevertheless, the latter may be utilising wet conditions to try and disperse to increase its distribution. All of this may seem very academic, but it does give reason for what is now described.

To assess surface movement of earthworms, fencing of the type already described could be employed, along with 
traps if desired. In addition it is possible to "encourage" dispersal by simulating the stimuli that might be responsible. In the simplest terms, inundation experiments could be derived to sprinkle water on to enclosed plots, at known rates, and record qualitatively and quantitatively the (nocturnal) emergence of earthworm species (and life stages). Naturally other factors such as temperature, brightness of the moon, and more may have an influence and need to be considered. Nevertheless, such manipulations might reveal a great deal on the dispersal behaviour of some of the species present in known communities.

Another series of relatively simple experiment (with countless subtle developments) might be employed to measure direct actions of earthworms on organic matter incorporation into soils. So-called "litter bag" experiments require known quantities of (air dried) organic matter from a site, to be enclosed in mesh constructions which permit, by the size of the mesh, access to certain groups of detritivorous soil organisms $[9,50]$. This requires some knowledge of the groups present and the type(s) of earthworm at the site but comparisons across different habitats, for example, or below different stands of trees can be revealing (see Figure 9). The litter bags need to be located at the soil surface (pinned down) or buried at chosen soil depths, to permit access to different ecological groups. In addition or instead, choice chamber experiments can be derived by offering laboratoryheld earthworms different types of known food materials in specifically designed mesocosms [51]. Where an earthworm, such as $L$. terrestris, feeds directly from the soil surface, experiments can also be set up to determine which food is eaten/removed to the burrow and if choices are made [52]. This can be determined by observation of which material has been disturbed after the event or more directly through recording of the actual behaviours in progress. Results from such laboratory experiments can show, for example, the preference for different agricultural/industrial waste organic materials spread on fields where L. terrestris is present (see Figure 10). Details on the type of technology required for this are provided below.

Surface-related behaviours, as described with respect to dispersal, can be recorded indirectly through trapping. Nevertheless feeding and mating at the soil surface, where it occurs, may be better recorded through direct means. The full mating behaviour of $L$. terrestris, including premating burrow visits by partners and the 3.5-hour mating itself, was first described after use of video recording using a simple security-type camera setup, linked to a basic video recorder [53]. More recent work has examined details of the mating more thoroughly [54]. This same technology was also used to obtain results for food choice in this species [52]. However, such work may now be considered costly and has been overtaken by more recent developments in the IT world, whereby a "webcam" can now be obtained relatively inexpensively for similar use. This may seem to be a contradiction of the ethos of this article, but as will be seen, costs here may be negligible. Recent work [55] has investigated, for example, the effects of pesticides and water inundation on earthworm behaviour. For further experiments in progress, examining light effects on surface-

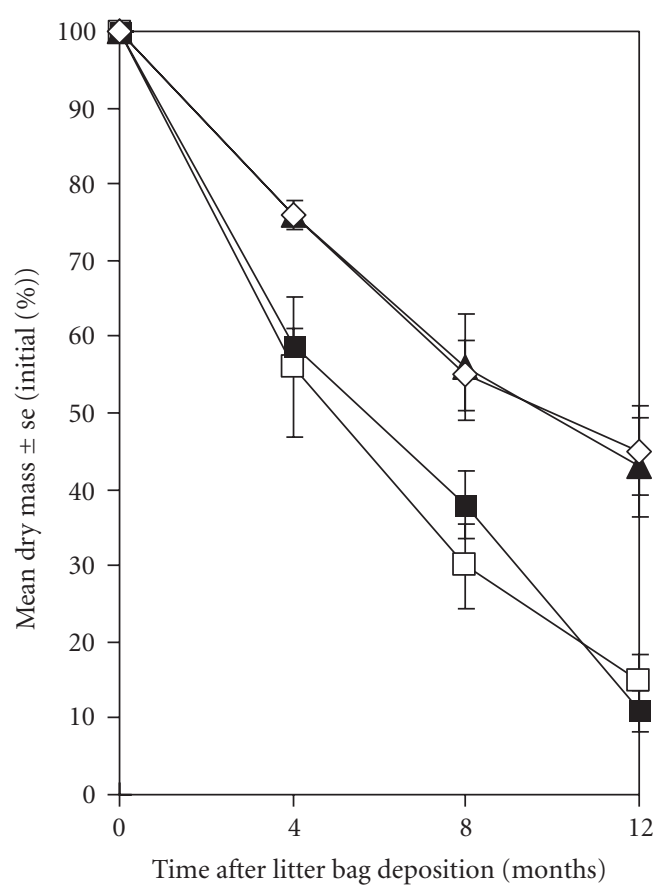

FIGURE 9: Decreasing mass of birch leaf litter from $3 \mathrm{~mm}$ mesh litter bags related to tree plots on the Isle of Rum; from known earthworm communities below pure stands of oak- $\square$; birch- $\square$; pine- $\boldsymbol{\Delta}$; on moorland- $\diamond$ (adapted from [9]).

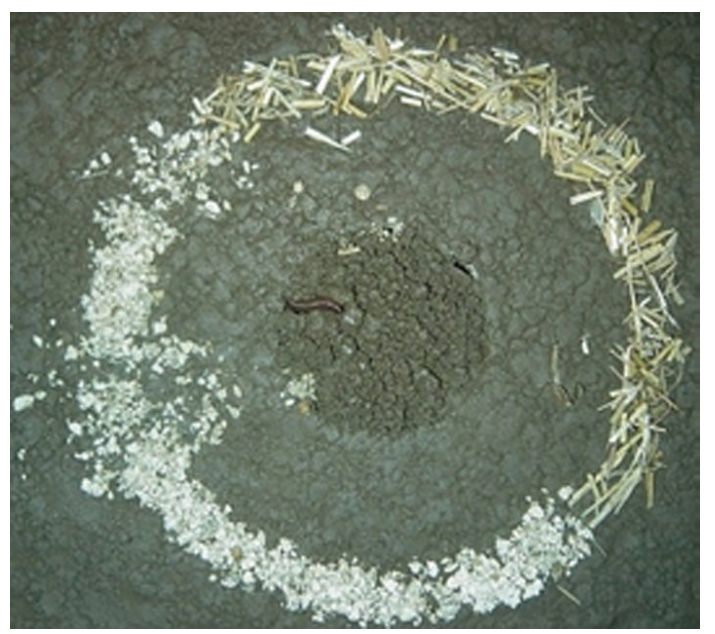

FIGURE 10: Results after one night of feeding by a single L. terrestris offered equal amounts of barley straw and waste paper pulp in a $0.25 \mathrm{~m}^{2}$ arena with the earthworm housed in a central cylinder of attached soil (from above).

related behaviours of earthworms, equipment was obtained including web cams $(n=4)$ and the appropriate software (for use on a standard PC) for less than \$100 (at 2009 prices). Figure 11 was obtained during this particular set of experiments housing animals in plastic tubes (drainpipes).

Behavioural work with earthworms may still be regarded as in its infancy, although some major revelations have occurred, particularly with $L$. terrestris $[53,54]$. From basic 


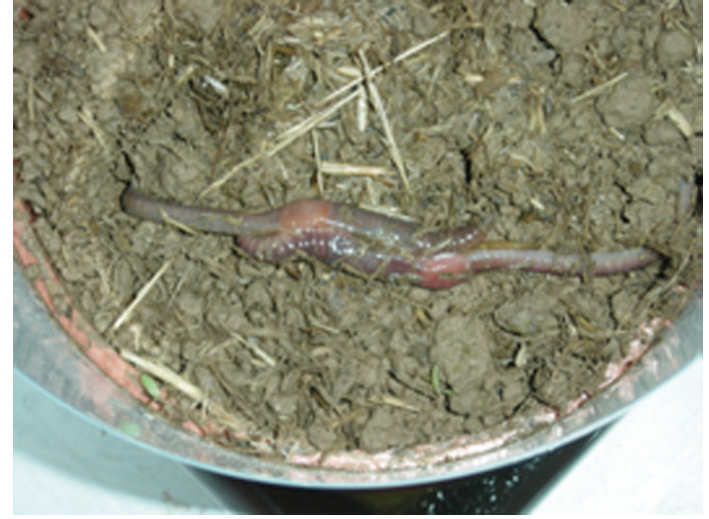

FIGURE 11: A pair of mating L. terrestris on the soil surface, revealed and photographed after sun rise.

observations of mating behaviour, through mate selection, to close scrutiny of copulatory interaction, has all been examined. Great scope still exists in the area of earthworm behaviour and some of the following questions could be addressed.

(i) Which species exhibit mass dispersal and which life stages are involved?

(ii) How much leaf litter is removed or consumed by earthworms in given habitats?

(iii) Can removal of organic matter into the soil be harnessed for soil improvement?

(iv) Is L. terrestris the only species that mates on the soil surface?

(v) Do other earthworm species show mate choice?

\section{Field Manipulation of Populations (Assisting the Plough)}

Where soils require an input of earthworms, augmentation can be brought about using the above informationcollection, selection for activities, and even selection for mass culture before field-release. Earthworms, because of their activities in the soil, are, where appropriate, considered as vital components of a healthy, fully functional system. Reviews of research have shown that, across the world and in numerous habitats, the provision of earthworms to sites where they were absent, assistance with recolonisation, or improvements to the type of conditions conducive to their survival can bring about marked positive changes in soil properties [56, 57].

Should areas exist that are devoid of earthworms, for known or unknown reasons, then one approach might be to (re)introduce them to site. Numerous methods are available to achieve this but most can be described simply as "collection and broadcast" using the type of collection techniques previously mentioned or "turf transfer", digging up and translocating soil with grass attached. Both have been

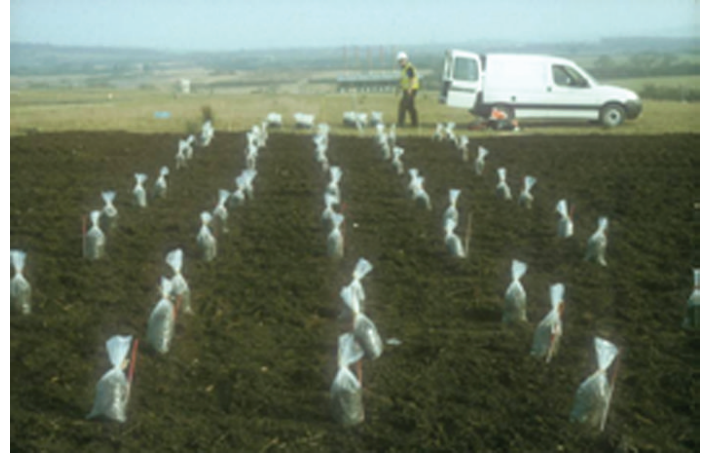

FIGURE 12: Two litre Earthworm Inoculation Units (EIUs) ready for inoculation into an organically-enriched landfill cap in the south of England.

used and have positive attributes but equally have less attractive features (see Table 3). To assist the reintroduction process, information gathered on earthworm life histories and requirements for culture have been coupled with further data relating to activities in the soil and interactions with other earthworm species [34, 40-43]. In this way a relatively simple technique, the Earthworm Inoculation Unit (EIU), was devised [26] seeking to overcome the problems associated with the existing techniques. Irreverently known as "worms in bags" this technique seeks to cultivate a starter culture of adults under optimal conditions over a period of a few months. After this time, population development within the plastic-bound units means that all life stages, adults, cocoons, and hatchlings ought to be present. The EIUs can then be transported to the desired inoculation site ready for introduction (see Figure 12). Inoculation requires the contents of the EIUs to be inserted into an appropriately sized hole in the soil, after the plastic envelope has been carefully removed.

The contents thereby retaining their original position in the soil profile and providing a protective microenvironment. Over the past two decades, results from both agricultural and post-industrial settings have been positive $[26,48]$. Spread of earthworms over one site at Calvert site was completed within a decade and positive interactions were recorded with the presence of alder trees (Alnus glutinosawhich fix nitrogen) and earthworm density [27]. At one of the sites, further investigations developed the EIU technique with addition of organic matter. This was a response to use of manure as "earthworm attractant traps" to augment assessment of the numbers and species present on site [26].

Addition of earthworms to sites where they are absent (for some reason) may be valuable and permit a number of questions to be addressed.

(i) What factors brought about the removal of earthworms?

(ii) What can be done to remedy the situation?

(iii) How can the success of the operation be measured (in terms of earthworms and soils)?

(iv) Can more be learned of earthworm populations from this type of work? 
TABLE 3: Relative Merits of existing Earthworm Inoculation Techniques (adapted from [26]).

\begin{tabular}{lcc}
\hline Technique & Advantages & Disadvantages \\
\hline Turf Cutting and relaying & Protective microenvironment & Densities usually low \\
& Cocoons transferred & Little control over species/numbers \\
& & Mainly shallow working worms \\
Cutting machines/labour required & Damage to collection site
\end{tabular}

Chemical/physical extraction with broadcasting
High densities possible

Species selection possible
Protective micro-environment absent

No cocoon transfer

Mainly deep burrowing worms

Worms may be injured during extraction

Laborious and expensive

Damage to collection site

Earthworm Inoculation Unit (EIU) method
Protective microenvironment

Species selection possible

Worms of known origin

Cocoons transferred

High densities possible

\section{Conclusion}

This article set out to demonstrate that low-technology methods are able to gain insights into fundamental questions relating to earthworms. Examples have been provided and direction given towards investigations asking relatively simple questions that can utilize these techniques. In addition to the sections described on collection, burrowing, behaviour, life history, and manipulation of earthworms, others which have only been hinted at or perhaps overlooked can also be developed, and many of those included have an amount of overlap within them. It is for the prospective researcher to identify the preferred niche area of investigation and progress it to potentially create a new angle within the existing fields of knowledge. Science tends to require funding in order to advance, but one critical aspect is the development of ideas and the creative use of available resources. Earthworm ecological research still has room for the use of basic tools.

\section{Acknowledgments}

The authors thank numerous site managers for access to sites over the years and Colman's of Norwich for provision of mustard powder.

\section{References}

[1] C. R. Darwin, The Formation of Vegetable Mould through the Action of Worms with Some Observations on Their Habits, John Murray, London, UK, 1881.
[2] C. A. Edwards and P. J. Bohlen, Biology and Ecology of Earthworms, Chapman \& Hall, Boca Raton, Fla, USA, 3rd edition, 1996.

[3] M. J. Shipitalo, V. Nuutinen, and K. R. Butt, "Interaction of earthworm burrows and cracks in a clayey, subsurfacedrained, soil," Applied Soil Ecology, vol. 26, no. 3, pp. 209-217, 2004.

[4] C. G. Jones, J. H. Lawton, and M. Shachak, "Organisms as ecosystem engineers," Oikos, vol. 69, no. 3, pp. 373-386, 1994.

[5] K. R. Butt and N. Grigoropoulou, "Earthworms from aughton woods: an ancient woodland in lancashire," Unpublished Report, The Wildlife Trust for Lancashire, Manchester and North Merseyside, March 2009, (Ref: WT09).

[6] K. R. Butt and C. N. Lowe, "Earthworms at mere sands wood nature reserve," Unpublished Report, The Wildlife Trust for Lancashire, Manchester and North Merseyside, October 2002, (Ref: CWEM3).

[7] K. R. Butt and J. Kostecka, "The earthworms of wistman's wood, dartmoor," Bulletin of the Devon Invertebrate Forum, vol. 7, pp. 13-17, 2001.

[8] K. R. Butt, C. N. Lowe, T. Beasley, I. Hanson, and R. Keynes, "Darwin's earthworms revisited," European Journal of Soil Biology, vol. 44, no. 3, pp. 255-259, 2008.

[9] K. R. Butt and C. N. Lowe, "Anthropic influences on earthworm distribution, Isle of Rum National Nature Reserve, Scotland," European Journal of Soil Biology, vol. 40, no. 2, pp. 63-72, 2004.

[10] K. R. Butt, "Earthworms of the Malham Tarn Estate (Yorkshire Dales National Park)," Field Studies, vol. 9, no. 4, pp. 701-710, 2000.

[11] K. R. Butt and C. N. Lowe, "Earthworms of the newton rigg estate," Unpublished Report, University of Cumbria, June 2009, (Ref ENRC 6/09). 
[12] S. R. Stürzenbaum, J. Andre, P. Kille, and A. J. Morgan, "Earthworm genomes, genes and proteins: the (re)discovery of Darwin's worms," Proceedings of the Royal Society B, vol. 276, no. 1658, pp. 789-797, 2009.

[13] C. J. Langdon, A. J. Morgan, J. M. Charnock, K. T. Semple, and C. N. Lowe, "As-resistance in laboratory-reared F1, F2 and F3 generation offspring of the earthworm Lumbricus rubellus inhabiting an As-contaminated mine soil," Environmental Pollution, vol. 157, no. 11, pp. 3114-3119, 2009.

[14] M. J. I. Briones, R. Bol, D. Sleep, D. Allen, and L. Sampedro, "Spatio-temporal variation of stable isotope ratios in earthworms under grassland and maize cropping systems," Soil Biology and Biochemistry, vol. 33, no. 12-13, pp. 1673-1682, 2001.

[15] ISO 23611-1, "Soil quality—sampling of soil invertebratespart 1: hand-sorting and formalin extraction of earthworms," ISO 23611-1, 2006.

[16] E. Eichinger, A. Bruckner, and M. Stemmer, "Earthworm expulsion by formalin has severe and lasting side effects on soil biota and plants," Ecotoxicology and Environmental Safety, vol. 67, no. 2, pp. 260-266, 2007.

[17] A. Gunn, "The use of mustard to estimate earthworm populations," Pedobiologia, vol. 36, no. 2, pp. 65-67, 1992.

[18] A. P. Lawrence and M. A. Bowers, "A test of the 'hot' mustard extraction method of sampling earthworms," Soil Biology and Biochemistry, vol. 34, no. 4, pp. 549-552, 2002.

[19] E. R. Zaborski, "Allyl isothiocyanate: an alternative chemical expellant for sampling earthworms," Applied Soil Ecology, vol. 22, no. 1, pp. 87-95, 2003.

[20] C. Pelosi, M. Bertrand, Y. Capowiez, H. Boizard, and J. RogerEstrade, "Earthworm collection from agricultural fields: comparisons of selected expellants in presence/absence of handsorting," European Journal of Soil Biology, vol. 45, no. 2, pp. 176-183, 2009.

[21] N. Eisenhauer, D. Straube, and S. Scheu, "Efficiency of two widespread non-destructive extraction methods under dry soil conditions for different ecological earthworm groups," European Journal of Soil Biology, vol. 44, no. 1, pp. 141-145, 2008.

[22] J. M. Blair, R. W. Parmelee, M. F. Allen, D. A. McCartney, and B. R. Stinner, "Changes in soil N pools in response to earthworm population manipulations in agroecosystems with different N sources," Soil Biology and Biochemistry, vol. 29, no. 3-4, pp. 361-367, 1997.

[23] S. L. Lachnicht, R. W. Parmelee, D. Mccartney, and M. Allen, "Characteristics of macroporosity in a reduced tillage agroecosystem with manipulated earthworm populations: implications for infiltration and nutrient transport," Soil Biology and Biochemistry, vol. 29, no. 3-4, pp. 493-498, 1997.

[24] N. Grigoropoulou and K. R. Butt, "Field investigations of Lumbricus terrestris spatial distribution and dispersal through monitoring of manipulated, enclosed plots," Soil Biology and Biochemistry, vol. 42, no. 1, pp. 40-47, 2010.

[25] A. C. Evans and W. J. Mc. L. Guild, "Studies on the relationships between earthworms and soil fertility. I. Biological studies in the field," Annals of Applied Biology, vol. 34, no. 3, pp. 307-330, 1947.

[26] K. R. Butt, J. Frederickson, and R. M. Morris, "The Earthworm Inoculation Unit technique: an integrated system for cultivation and soil-inoculation of earthworms," Soil Biology and Biochemistry, vol. 29, no. 3-4, pp. 251-257, 1997.
[27] K. R. Butt, C. N. Lowe, J. Frederickson, and A. J. Moffat, "The development of sustainable earthworm populations at Calvert Landfill Site, UK," Land Degradation \& Development, vol. 15, no. 1, pp. 27-36, 2004.

[28] K. R. Butt and V. Nuutinen, "The dawn of the dew worm," Biologist, vol. 52, no. 4, pp. 218-223, 2005.

[29] K. R. Butt and C. N. Lowe, "Presence of earthworm species within and beneath Lumbricus terrestris (L.) middens," European Journal of Soil Biology, vol. 43, supplement 1, pp. S57S60, 2007.

[30] M. J. Shipitalo and K. R. Butt, "Occupancy and geometrical properties of Lumbricus terrestris L. burrows affecting infiltration," Pedobiologia, vol. 43, no. 6, pp. 782-794, 1999.

[31] V. Nuutinen and K. R. Butt, "Interaction of Lumbricus terrestris L. burrows with field subdrains," Pedobiologia, vol. 47, no. 5-6, pp. 578-581, 2003.

[32] V. Nuutinen and K. R. Butt, "Worms from the cold: lumbricid life stages in boreal clay during frost," Soil Biology and Biochemistry, vol. 41, no. 7, pp. 1580-1582, 2009.

[33] A. C. Evans, "Method of studying the burrowing activity of earthworms," Annual Magazine of Natural History, vol. 11, pp. 643-650, 1947.

[34] N. Grigoropoulou, K. R. Butt, and C. N. Lowe, "Effects of adult Lumbricus terrestris on cocoons and hatchlings in Evans' boxes," Pedobiologia, vol. 51, no. 5-6, pp. 343-349, 2008.

[35] M. Joschko, O. Graff, P. C. Müller, et al., "A non-destructive method for the morphological assessment of earthworm burrow systems in three dimensions by X-ray computed tomography," Biology and Fertility of Soils, vol. 11, no. 2, pp. 88-92, 1991.

[36] J. H. Lawton, "The ecotron facility at silwood park: the value of "Big Bottle" experiments," Ecology, vol. 77, no. 3, pp. 665-669, 1996.

[37] S. Naeem, J. H. Lawton, L. J. Thompson, S. P. Lawler, and R. M. Woodfin, "Biotic diversity and ecosystem processes: using the Ecotron to study a complex relationship," Endeavour, vol. 19, no. 2, pp. 58-63, 1995.

[38] L. Černosvitov and A. C. Evans, Lumbricidae (Annelida). With a Key to the Common Species, Synopses of the British Fauna, no. 6, The Linnean Society of London, London, UK, 1947.

[39] R. W. Sims and B. M. Gerard, Earthworms. Notes for Identification of British Species, R. S. K. Barnes and J. H. Crothers, Eds. Synopses of the British Fauna, no. 31, Linnean Society of London and the Estuarine and Coastal sciences Association, 1999.

[40] C. N. Lowe and K. R. Butt, "Culture techniques for soil dwelling earthworms: a review," Pedobiologia, vol. 49, no. 5, pp. 401-413, 2005.

[41] K. R. Butt, "Depth of cocoon deposition by three earthworm species in mesocosms," European Journal of Soil Biology, vol. 38, no. 2, pp. 151-153, 2002.

[42] K. R. Butt, J. Frederickson, and R. M. Morris, "Effect of earthworm density on the growth and reproduction of Lumbricus terrestris L. (Oligochaeta: Lumbricidae) in culture," Pedobiologia, vol. 38, no. 3, pp. 254-261, 1994.

[43] K. R. Butt, "Interactions between selected earthworm species: a preliminary, laboratory-based study," Applied Soil Ecology, vol. 9, no. 1-3, pp. 75-79, 1998.

[44] K. R. Butt, "The effects of temperature on the intensive production of Lumbricus terrestris L. (Oligochaeta: Lumbricidae)," Pedobiologia, vol. 35, no. 4, pp. 257-264, 1991.

[45] K. R. Butt and C. N. Lowe, "A viable technique for tagging earthworms using visible implant elastomer," Applied Soil Ecology, vol. 35, no. 2, pp. 454-457, 2007. 
[46] Northwest Marine Technology, June 2009, http://www.nmt .us/products/vie/vie.htm.

[47] K. R. Butt, M. J. I. Briones, and C. N. Lowe, "Is tagging with visual implant elastomer a reliable technique for marking earthworms?" Pesquisa Agropecuaria Brasileira. In press.

[48] V. Nuutinen, M. Nieminen, and K. R. Butt, "Introducing deep burrowing earthworms (Lumbricus terrestris L.) into arable heavy clay under boreal conditions," European Journal of Soil Biology, vol. 42, supplement 1, pp. S269-S274, 2006.

[49] J. G. Mather and O. Christensen, "Surface movements of earthworms in agricultural land," Pedobiologia, vol. 32, no. 56, pp. 399-405, 1988.

[50] C. A. Edwards and G. W. Heath, "The role of soil animals in breakdown of leaf material," in Soil Organisms, J. Doekson and J. van de Drift, Eds., pp. 76-84, North-Holland, Amsterdam, The Netherlands, 1963.

[51] B. M. Doube, O. Schmidt, K. Killham, and R. Correll, "Influence of mineral soil on the palatability of organic matter for lumbricid earthworms: a simple food preference study," Soil Biology and Biochemistry, vol. 29, no. 3-4, pp. 569-575, 1997.

[52] K. R. Butt, M. A. Nieminen, T. Sirén, E. Ketoja, and V. Nuutinen, "Population and behavioural level responses of arable soil earthworms to boardmill sludge application," Biology and Fertility of Soils, vol. 42, no. 2, pp. 163-167, 2005.

[53] V. Nuutinen and K. R. Butt, "The mating behaviour of the earthworm Lumbricus terrestris L. (Oligochaeta: Lumbricidae)," Journal of Zoology, vol. 242, pp. 783-798, 1997.

[54] N. K. Michiels, A. Hohner, and I. C. Vorndran, "Precopulatory mate assessment in relation to body size in the earthworm Lumbricus terrestris: avoidance of dangerous liaisons?" Behavioral Ecology, vol. 12, no. 5, pp. 612-618, 2001.

[55] J. Valckx, A. Pennings, G. Govers, M. Hermy, and B. Muys, "Dispersal of the earthworm Lumbricus terrestris L., in an experimental setup," in Proceedings of the International Colloquium on Soil Zooolgy, Curitiba, Brazil, September 2008.

[56] G. H. Baker, G. Brown, K. Butt, J. P. Curry, and J. Scullion, "Introduced earthworms in agricultural and reclaimed land: their ecology and influences on soil properties, plant production and other soil biota," Biological Invasions, vol. 8, no. 6, pp. 1301-1316, 2006.

[57] J. P. Curry, "The Ecology of Earthworms in reclaimed soils and their influence on soil fertility," in Earthworms in Waste and Environmental Management, C. A. Edwards and E. F. Neuhauser, Eds., pp. 251-261, SPB Academic, The Hague, The Netherlands, 1988. 

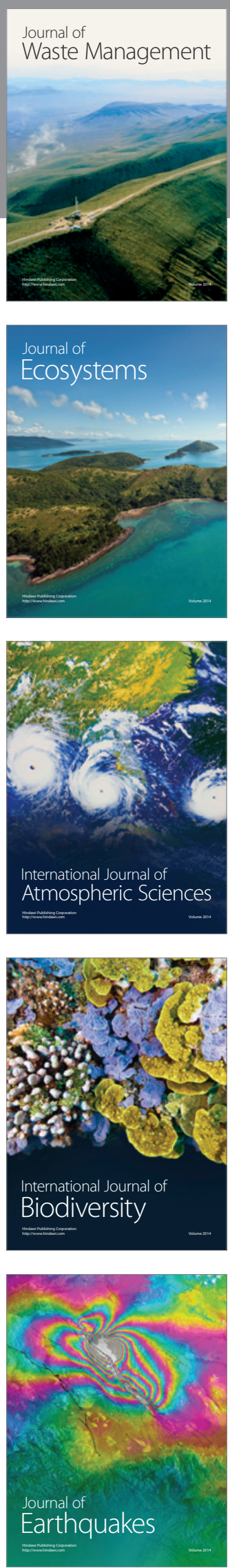
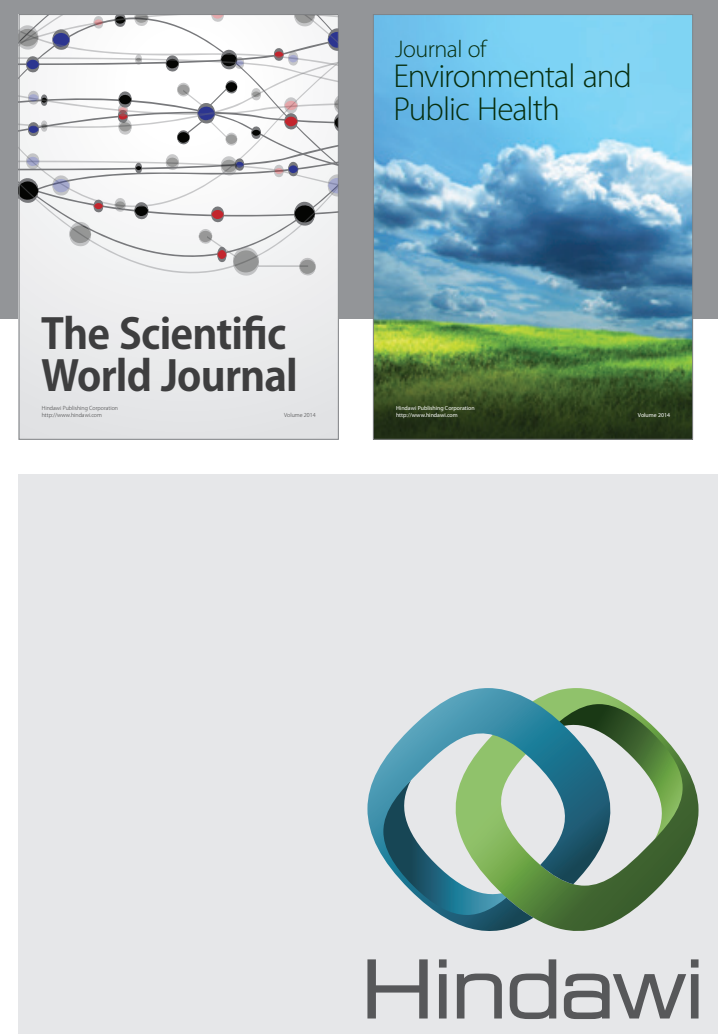

Submit your manuscripts at

http://www.hindawi.com
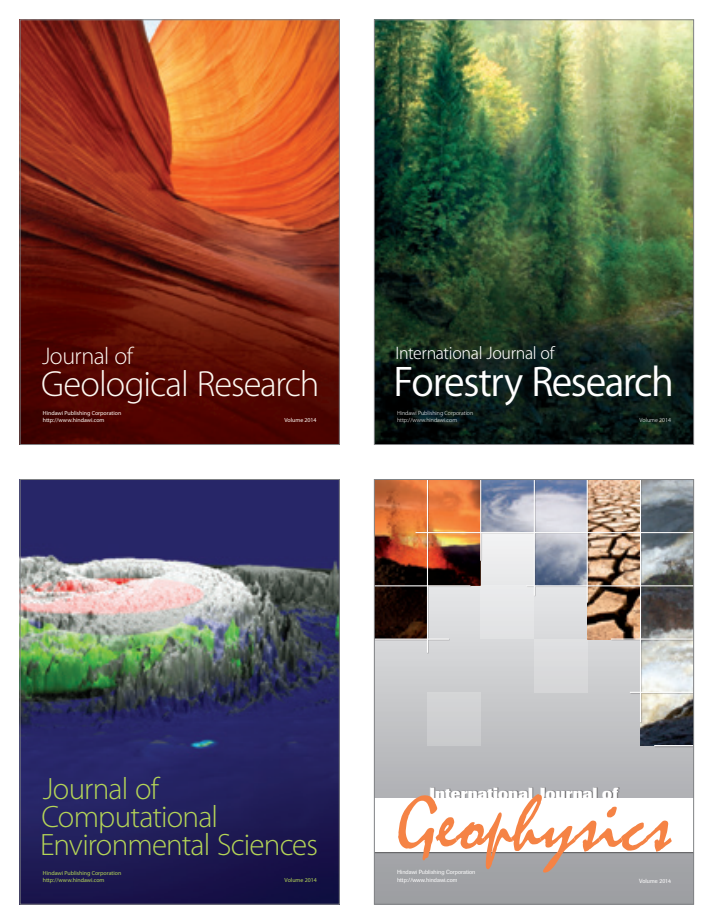
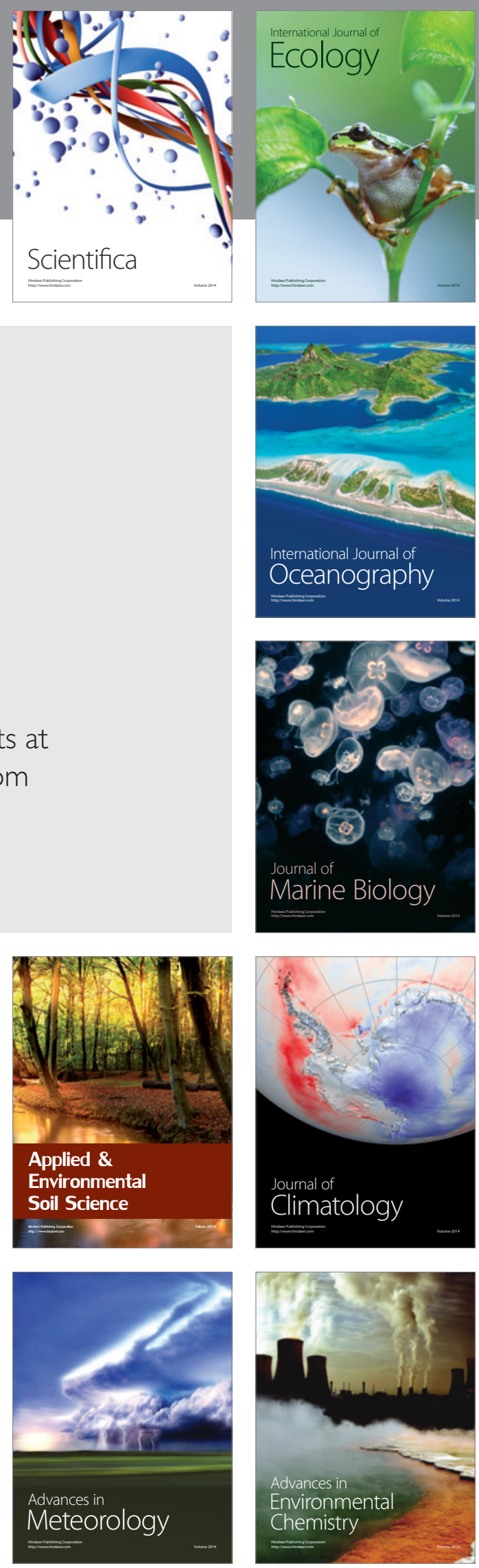